\title{
Impact of Quality Healthcare Equipment And Physical Structure on Nhis-Hmo Outpatient Enrollees' Perception In Lagos Hospitals
}

Abigail Affiong Mkperedem ( $\sim$ abigaileyo23@gmail.com )

Landmark University https://orcid.org/0000-0001-8855-1250

Peter B Ogunlade

Landmark University

Chisaa IGBOLEKWU

Landmark University

Festus Asamu

Landmark University

Bamidele Rasak

Landmark University

Ogadimma ARISUKWU

Landmark University

\section{Research}

Keywords: Perception, National Health Insurance Scheme, Health Maintenance Organisation, Healthcare equipment, Healthcare facility

DOI: https://doi.org/10.21203/rs.3.rs-86152/v1

License: (c) (i) This work is licensed under a Creative Commons Attribution 4.0 International License. Read Full License 


\section{Abstract}

This study assess enrollees' perception of Health care facility's (HCFs) physical structure and equipment quality across 9 accredited National health insurance/ Health maintenance organisation (NHIS-HMO) providing healthcare facilities within the 3 local government areas in Lagos, Nigeria.

Anchored on the phenomenology of time consciousness and the filter theory of attention, the study methodology was triangulated using survey method and in-depth interview. A total of 252 questionnaires and 5 in-depth interviews (IDIs) were used to elicit data from selected respondents using simple random and convenient sampling technique. There were differences between the survey result and the in-depth interview (IDIs) responses in terms of structural awareness in contrast with access to treatment equipments. $61.1 \%$ of the respondents agreed that the physical environment of the HCF was conducive, $61.5 \%$ agreed to the presence of standard and functional medical equipments in the HCF. With regards to the quality rating, $55.1 \%$ perceived the quality of HCFs physical structure and equipment fairly positive while $30.6 \%$ of the respondents perceived it negatively. From the group comparisons, the Chi-Square results $\left(P<0.01, \chi^{2}(16)=66.750\right)$ revealed significant correlations between quality of HCFs physical environment and equipment and enrollees perception. The Spearman's correlation was also positive at .064. These findings indicate that the tangible aspects of healthcare service are significant in health outcomes and should be given priority to ensure consistency in quality health promotion.

\section{Introduction}

The problem of quality has slowly become a big part of our lives and of culture as a whole; it is difficult to describe quality because of its subjective existence and intangible characteristics that everyone wants it to be quality can be almost anything. Although, no single universally accepted definition exists, quality has been defined as "value" by [1]; "excellence" by [2]. Research evidence indicates that the quality of service can be measured in five ways: service efficiency, service provider responsiveness, service provider assurance; consumer empathy and measurable proof of service quality [3]. Amenities components of quality in healthcare include characteristics such as comfortable physical environment and excellent service delivery [4]. The different views expressed in the definition of quality character are context determined and also dependent on the perceived perspective of the individual authors'.

Several studies have been conducted to measure what areas of health care service are considered important and significant in building necessary cues in patient's experience. For instance, [4] viewed healthcare quality as applying technical and medical science in such a way as that health benefits are optimised without increasing risk. Similar to [5] five categories of quality healthcare which included environmental attribute, Donabedian amenities for quality check also included features such as comfort of physical surroundings and attributes of the organisation towards service provision. Consequently, the main objective of this study is to assess enrollees' perception of Healthcare facility's (HCFs) physical structure and equipment quality across selected healthcare facilities (HCFs/ HCPs) in Lagos, Nigeria. 


\section{Literature Review}

\section{Quality of Health Care Facilities}

Methodical research work regarding the effect of healthcare physical surroundings on consumers' welfare and health outcome conducted by [6] revealed a positive correlating importance between the healthcare environment and the patients' health outcome. The Cochrane Database of Systematic Reviews included a hundred and two works by [7] where the investigated interventions were: 'positive distractors' which included 2 studies on aromas, 5 audiovisual studies, a study on decoration and 85 studies on music. While the multifaceted interventions had 2 studies, physical change to minimize environmental stress included interventions such as; a study each on the type of bedroom, lighting, and temperature, 3 studies on the quality of air, 2 flooring studies, and 1 study assessing furniture and furnishings.

Overall, patient-account revealed the ability of music to lessen health outcomes like apprehension; on the other hand, physiological effects, and drug use contribution had little proof. With the exception of quality of air, few researches accepted or denied the introduction of physical changes. It was discovered by the incorporated research that the physical changes in the hospital environment did not cause any damage or harm. Following the incorporated criterion incorporated to assess no studies was found on art, interventions to reduce HCFs noise, patient controls, and technologies; avenues to seek aid, accessibility to nature for example, through gardens, balcony, window space and ceilings.

The significance and implications of the physical surroundings as it affects patient's wellbeing was clearly stated in a simple outline by [8]. In contemporary time, studies indicate that the potential consequences attached with healthcare facilities physical environmental cues on patients' recuperation and welfare has obtained considerable attention.

The Drahota's study laid bare the capability of environmental factors in the production of optimistic results in health consumers outcomes, an idea referred to as 'healing environments'. The surrounding physical state in healthcare facilities has the ability to affect and influence health consumer's perception. The 'healing environments' ideology makes reference to cognitive effects of the physical environment through neurophysiological processing (sensory perception). One significant study tracked the recovery of patients in hospitals while viewing vegetation as opposed to structures, and found that those with a view to nature recovered faster [9].

\section{Theoretical Perspectives}

\section{Perception of HCFs physical structure and equipment quality through the lens of Edmund Husserl's Phenomenology of time consciousness}

The study of "phenomena" (appearance of things, or how objects emerge in individual's experience, or in what forms individual's experience objects, thus the meanings objects have in our perception at a specific time is regarded as time conscious phenomenology. 
The phenomenologist [9] assumes that intentional consciousness is related with universal contents, this can be interpreted to mean that perception, recalling; imagining and willingness are intentional in its very existence as conscious actions of the moment, hence, time conscious phenomenology assumes that our physical awareness concerning things in our surrounding or the appearance of things in our minds eye (perception, experience, thoughts, and memory) is time-related [10].

Although the intentional ideology possesses an undertone of wilful interest, it essentially showcases the connection consciousness has with surrounding objects. Our perception, according to classical Husserlian phenomenology, is geared (represents or intended) towards things through particular concepts, thoughts, ideas, and pictures temporarily. Husserl referred to the various structure of experience as "intentionality" because; the directedness of perception towards objects within the physical sphere possesses consciousness attributes.

One important implication of this theory is that it explores the composition of consciousness in the formation of perception concerning an object experienced within a particular time.

The connection between this research work and the phenomenology of time-consciousness is that it seeks to account for intentionality in enrollees perception guided by experience over time.

\section{Perception of HCFs physical structure and equipment quality through the len of Attention theory}

A major proponent of the attention theory, [11] suggested that tangible features present in the environment at specific timing are stored in a limitless capacity sensory buffer for cues processing and selection. Individuals then decide on which cues are to be given attention and which ones to avoid or omit (basically, the physical attributes of cues allows them to pass through the filtering process).

We may better characterize our environment as an environment of stimuli. Stimuli

Influence all or every one of our senses. Although, not all of the sensory clues within an individual's physical environment are listened or taken in at the same time but the presence of multitude of stimuli has the ability to overpower the human sense of feeling, hearing, touching, tasting and smelling. Because people cannot uphold simultaneous perceptible views to every stimulus exposed to in their physical setting, the clutter of cues observed are usually filtered after being taken in, and only a few are acceptable into the individual's mind. Such filters according to [12] are placed initially at the sensory filter for recording but gradually they begin to move into the perception filter phase.

Information that successfully passes through these filters is remembered, attached with meanings and thereafter, kept in the memory to be recalled for future use. Similarly, Naïve Realism emphasizes the function of perceptual experience involving the direct consciousness of the mind to filter independent objects. This filtering ability is instantly apparent to the mind once we experience external objects. Individual's perceptional experiences are made up of their mind-independent objects as well as its comprising features. At such, we are connected to those objects by our experiences and the unique quality of perception is attributed to objects that are independent of the mind's wit. In this way, when a 
patient enters the health care hospital, the patient sees every visible part of the health service provider (HCPs), which is an external entity. The experience is of the HCP-such a patient is conscious of the object (HCP) directly-and the sensory attributes which appears are elements of the mind-independent item.

Overall, the filter theory can be seen in the light of one of the major naïve realist defenders $[13,14,15,16]$ who viewed experience as the relation linking persons with the object of awareness. To this end, the filter theory can be said to focus on the ability of the individual mind to take up, process and maintain certain signals from the HCF context, while others are rightly dismissed, thereby making perception a sequence involving the knowledge of mentally autonomous objects.

The connection between this research work and the filter theory of attention is to depict how enrollees subsequently attaches meanings to the cues and how such interpretations are attached to a stimulus exposed to during healthcare. These may involve good or bad experiences, but, such involvement depends on the force within the cue. Whatever personal understanding or meanings the enrollee makes regarding the accessed service will be kept in the memory to be recalled in the future when deciding about services to patronise in that particular HCF.

The Phenomenology of time consciousness as well as the attention theories was adopted to guide the study in investigating how perceptions are dependent on enrollees exposure to stimuli present in cues (whether good or bad) as an essential reality of the human consciousness. Enrollees perception of healthcare facility's physical structure and equipment can therefore be said to be linked to their given meanings to the objects encountered, both successional (eg, a mobile X-ray machine) or static (eg, a hospital building), this filtered cues are used in developing basic assumptions regarding the objects quality at the point of contact.

\section{Methodology}

The study triangulates between quantitative (questionnaires) and qualitative (In-depth interviews (IDIs) data collection method. The population comprises of NHIS and HMO enrollees' between 18 years and 65years visiting selected public and private hospitals in Eti-Osa, Ikeja and Ibeju-Lekki Local Government Areas (LGAs) within the three senatorial districts in Lagos, Nigeria. The accredited public and private HCFs included: (1) St. Mary Specialist Hospital, (2) Awoyaya hospital, (3) Blue cross hospital, (4) Unity hospital, (5) The Eko hospital, (6) General hospital Akodo, (7) Budo specialist hospital, (8) Etta Atlantic memorial hospital, and (9) St. Nicholas hospital. The selection of both public and private HCPs was to depict the two dominant healthcare facility systems in Nigeria.

Multistage sampling technique was used to select the study participants. Simple random sampling was employed at each stage to reduce selection bias. The first stage involved clustering the twenty (20) Local Governments into the three senatorial districts, selecting only one Local Government from each district through balloting. Stage two involved obtaining a list of all registered HCPs within the local governments and stratifying them into private and government administered. At this stage, convenience method was 
used to choose three HCFs accredited by NHIS to provide primary, secondary and or tertiary services to be sampled in the study.

Factor analyses of subjects-to-variables ratio [17]; with a minimum of ten (10) subjects per variable [18] in the study instrument was utilised to choose a sample size of 240 enrollee respondents which was calculated ( 20 subjects per each of the 12 variables in the study instrument). The minimum sample size of approximately $266(240 / 0.9)$ patients was reached after adjusting for $10 \%$ non-response to the questionnaire.

A total of 252 copies of a structured questionnaire and 5 IDIs were used to elicit data from the respondents. The quantitative data collected was analysed using the normal descriptive statistics of frequencies and simple percentages with the help of the Statistical Package for Social Sciences version 20 (SPSS 20). The qualitative data was analyzed using inductive content analysis. To find the relationship between the variables and test of hypotheses, the contingency Chi-Square and the Spearman's correlation analysis was performed.

The quality indicator variables were presented on a five (5) - point likert scale: SA-Strongly agree (5), AAgree (4), U-Undecided (3), D- Disagree (2) and SD-Strongly disagree (1), [19]. During hypotheses testing, these ordered categories were transformed, summated and the responses converted into five (5) categories termed as five (very good), four (good), three (undecided), two (bad) and one (very bad). The perception variables were measured using likert-type items of five ordered categories, rated from five (very high in quality) to one (very low in quality).

Ethical clearance was obtained from the Lagos State Government Health Service Commission before the study commenced with an ethical clearance code of: LSHSC/88/S.3/II/257. The management of all HCFs used in the study gave written approval for the implementation of the study. Study objectives, confidentiality of responses, benefits and the right to refuse were explained to participants of IDIs, of which written informed consent was obtained from willing participants and those without formal western education had the content translated to them in the locally spoken Yoruba language.

\section{Results}

\section{Socio-demographic characteristics of the respondents}

Table 1: Socio-demographic characteristics of respondents 


\begin{tabular}{|c|c|c|}
\hline Variable & $\begin{array}{l}\text { Frequency } \\
(\mathrm{N}=252)\end{array}$ & $\begin{array}{l}\text { Percentage } \\
\text { (\%) }\end{array}$ \\
\hline \multicolumn{3}{|l|}{ Sex } \\
\hline Male & 82 & 32.5 \\
\hline Female & 170 & 67.5 \\
\hline \multicolumn{3}{|l|}{ Age } \\
\hline $18-20$ & 22 & 8.7 \\
\hline $21-30$ & 66 & 26.2 \\
\hline $31-40$ & 93 & 36.9 \\
\hline $41-50$ & 25 & 9.9 \\
\hline $51-65$ & 46 & 18.3 \\
\hline \multicolumn{3}{|l|}{ Marital Status } \\
\hline Single & 70 & 27.8 \\
\hline Married & 134 & 53.2 \\
\hline Others & 48 & 19.0 \\
\hline \multicolumn{3}{|l|}{ Educational Qualification } \\
\hline No Formal Education & 22 & 8.7 \\
\hline First leaving school certificate & 15 & 6.0 \\
\hline Secondary School & 34 & 13.5 \\
\hline OND/NCE & 32 & 12.7 \\
\hline HND/B.Sc & 101 & 40.1 \\
\hline M.Sc/MBA/M.Ed & 38 & 15.1 \\
\hline P.Hd & 10 & 4.0 \\
\hline \multicolumn{3}{|l|}{ Public-Private Partnership } \\
\hline Public/ NHIS & 47 & 18.7 \\
\hline Private/ HMO & 205 & 81.3 \\
\hline \multicolumn{3}{|l|}{ Public-Private HCFs } \\
\hline Public HCFs & 44 & 17.5 \\
\hline Private HCFs & 208 & 82.5 \\
\hline
\end{tabular}




\section{Source: Field Survey (2019)}

From Socio- Demographic characteristics of respondents in Table 1, majority (67.5\%) of the respondents were females. This percentage of the female respondents corresponds with the last census report. Again, a larger proportion $(53.2 \%)$ of the respondents was married. The majority $(36.0 \%)$ of the respondents fall within the age bracket of 31 and 40 which represents the active working population with a mean interval of 3.0278. Although more expensive, larger proportion of the respondents $(81.3 \%)$ subscribed to the private $\mathrm{HMO}$ plan and $82.5 \%$ accessed care in private HCFs.

\section{Table 2: Distribution of respondents' on quality of HCF's physical structure and equipment}

Questionnaire Item

Responses

$\begin{array}{lllll}\text { Strongly } & \text { Agree } & \text { Undecided } & \begin{array}{l}\text { Disagree } \\ (\%)\end{array} & \begin{array}{l}\text { Strongly } \\ \text { Disagree }\end{array}\end{array}$

(\%)

\begin{tabular}{|c|c|c|c|c|c|c|}
\hline $\begin{array}{l}\text { The physical environment } \\
\text { of the HCF is conducive }\end{array}$ & $\begin{array}{l}60 \\
(23.8 \%)\end{array}$ & $\begin{array}{l}94 \\
(37.3 \%)\end{array}$ & $\begin{array}{l}32 \\
(12.7 \%)\end{array}$ & $\begin{array}{l}36 \\
(14.3 \%)\end{array}$ & $\begin{array}{l}30 \\
(11.9 \%)\end{array}$ & $\begin{array}{l}252 \\
(100 \%)\end{array}$ \\
\hline $\begin{array}{l}\text { The medical equipment is } \\
\text { standard and functional }\end{array}$ & $\begin{array}{l}42 \\
(16.7 \%)\end{array}$ & $\begin{array}{l}113 \\
(44.8 \%)\end{array}$ & $\begin{array}{l}29 \\
(11.5 \%)\end{array}$ & $\begin{array}{l}40 \\
(15.9 \%)\end{array}$ & $\begin{array}{l}28 \\
(11.1 \%)\end{array}$ & $\begin{array}{l}252 \\
(100 \%)\end{array}$ \\
\hline
\end{tabular}

\section{Source: Field Survey (2019)}

In Table 2, Respondents assessment of the HCF tangible aspects of service reveals majority (61.1\%) from a combined weight of Strongly Agree (SA) and Agree (A) accepted the conducive state of the HCFs physical environment. Similarly, 61.5\% combined weight of Strongly Agree (SA) and Agree (A) shows HCF possession of standard and functional equipment compare to the combined weight (27\%) of Disagree (D) and Strongly Disagree (SD) respondents' on the HCF equipment quality.

Table 2b: Distribution of respondents' perception on quality of HCF's physical structure and equipment 


\begin{tabular}{|c|c|c|c|c|c|c|}
\hline \multirow[t]{2}{*}{ Questionnaire Item } & \multicolumn{5}{|l|}{ Responses } & \multirow[b]{2}{*}{ Total } \\
\hline & $\begin{array}{l}\text { Very High } \\
\text { perception } \\
(\%)\end{array}$ & $\begin{array}{l}\text { Fairly } \\
\text { High } \\
\text { perception } \\
(\%)\end{array}$ & $\begin{array}{l}\text { Average } \\
\text { perception } \\
(\%)\end{array}$ & $\begin{array}{l}\text { Low } \\
\text { perception } \\
(\%)\end{array}$ & $\begin{array}{l}\text { Very Low } \\
\text { perception } \\
(\%)\end{array}$ & \\
\hline $\begin{array}{l}\text { Respondents' rating } \\
\text { of HCF physical } \\
\text { structure and } \\
\text { equipment quality }\end{array}$ & $\begin{array}{l}53 \\
(21.0 \%)\end{array}$ & $\begin{array}{l}86 \\
(34.1 \%)\end{array}$ & $\begin{array}{l}36 \\
(14.3 \%)\end{array}$ & $\begin{array}{l}36 \\
(14.3 \%)\end{array}$ & $\begin{array}{l}41 \\
(16.3 \%)\end{array}$ & $\begin{array}{l}252 \\
(100 \%)\end{array}$ \\
\hline
\end{tabular}

\section{Source: Field Survey (2019)}

Table $2 \mathrm{~b}$ reveals that majority of the respondents (55.1\%) from a combined weight of very high and fairly high rated positively while $30.6 \%$ combined weight of low and very low perception rated the HCFs physical structure and equipment negatively.

\section{Test of hypothesis}

$\mathrm{H}_{0}$ : There is no significant relationship between enrollees' perception and HCFs physical structure and equipment quality.

$\mathrm{H}_{1}$ : There is significant relationship between enrollees' perception and HCFs physical structure and equipment quality.

Decision criterion: Reject $\mathrm{H}_{0}$ if the calculated (observed value) of chi-square $\left(\chi^{2} \mathrm{c}\right)$ is found to be greater than the critical (table) value of chi-square $\chi^{2} t(0.01)$, if not, do not reject. Data from Table 2 and $2 b$ were cross tabulated and used in testing this hypothesis. The result is shown in table 3. 
Table 3: Cross tabulation of relationship between enrollees' perception and quality of

HCFs physical structure and equipment

\begin{tabular}{llllll}
\hline Variables & $\begin{array}{l}\text { Very high } \\
\text { Perception } \\
\text { (\%) }\end{array}$ & $\begin{array}{l}\text { Average } \\
\text { Perception } \\
\text { (\%) }\end{array}$ & $\begin{array}{l}\text { Very low } \\
\text { Perception } \\
\mathbf{( \% )}\end{array}$ & Total & $\chi^{2}$ \\
Very Good & $29(48.3)$ & $8(13.3)$ & $23(38.3)$ & $60(100.0)$ & $\chi^{2}=66.750$ \\
Good & $70(73.7)$ & $8(8.4)$ & $17(17.9)$ & $95(100.0)$ & $r=.064$ \\
Undecided & $11(35.5)$ & $6(19.4)$ & $14(45.2)$ & $31(100.0)$ & $\mathrm{P}=.000$ \\
Bad & $17(44.8)$ & $8(21.1)$ & $13(34.3)$ & $38(100.0)$ & $\mathrm{df}=16$ \\
Very bad & $12(42.9)$ & $6(12.8)$ & $10(35.8)$ & $28(100.0)$ & \\
& & & & & \\
Total & $\mathbf{1 3 9 ( 5 5 . 1 )}$ & $\mathbf{3 6 ( 1 4 . 3 )}$ & $\mathbf{7 7 ( 3 0 . 6 )}$ & $\mathbf{2 5 2 ( 1 0 0 . 0 )}$ & \\
\hline
\end{tabular}

Source: Field Survey 2019

** Correlation is significant at the 0.01 level

Table 3 shows the relationship between enrollees' perception and the quality of physical structure and equipment. A total of ninety-nine (99) respondents' who are very high in perception who also saw the quality of physical structure and equipment as very good and good is higher than those (29) who are very high in perception but saw the quality of physical structure and equipment as bad and very bad. Also the 99 respondents' is higher than those (23) who are very low in perception and saw the quality of physical structure and equipment as very bad and bad. As we see from these group comparisons therefore, we can see empirically that there is a relationship between perception and quality of physical structure and equipment.

Inferential statistics supports this empirical observation as shown in the calculated $\chi^{2}(16)=66.750$ is higher than the chi-square table $(\mathrm{P}<0.01)$. Therefore the null hypothesis is rejected and the alternate hypothesis accepted. Also, the Spearman's correlation $(r)=.064$ shows a positive relation between perception and quality of illness treatment.

\section{Content Analyses}

Regarding structure, respondents' were interviewed regarding the tangible physical aspects of the HCFs, as observed in one of the public HCF, the windows in the female ward were all broken, with little or no greenery. A participant asserted thus:

The atmosphere continually reeks of offensive odour ranging from vomit to corpse embalmment. There is always that frightful stench. You have to use a nose mask to curtail the smell (IDI 1. Female. 44)

As observed regarding examination, the assessment of the structural quality also includes the use of standard and functional equipment in treatment and a respondent' asserted thus:

I noticed that out-of-pocket paying patients were coming out from various units of the hospital that conducts tests, scan, dialysis etc, so, I am sure the equipments are standard and functional, but as an 
enrollee, you don't have access to such luxury as the popular song in the mouth of every personnel is "it's not covered" making me wonder what the scheme actually covers (IDI 2. Male. 30)

These responses above suggest that healthcare facilities were in possession of standard and functional equipment, which was accessed by out-of-paying patients but enrollees were deprived of such evident based means of healthcare service. It is evident that despite the fact that hospitals are supposedly the place where patients despair is abated, the physical state can affect how patients perceive the quality of services. Thus validifying the 'cleanliness is next to godliness' slogan.

Furthermore, the responses show that an enrollees insurance plan determines the quality of service accessed at hospitals and the health plans also affects the quality of service rendered, such services that involves access to equipments testing kits. This therefore raises the concern for the quality of services accessed at the HCFs by the poor and low economy enrollees'.

Conclusively, IDI statements reflected that the patients' perceptive insight builds from the cues gathered during comprehensive healthcare services experience.

\section{Discussion}

The major aim of this research was to "assess enrollees' perception of quality of HCFs physical structure and equipment". The null hypothesis "quality of HCFs physical structure and equipment does not affect enrollees' perception significantly" was postulated to direct the study. The research shows that enrollees' takes into cognisance the intangible aspect of healthcare services. The survey result revealed that HCFs environment were conducive, and the equipment was of functional and of standard quality.

Data from Table 2 and Table $2 \mathrm{~b}$ were cross tabulated to test the second hypothesis. The contingency chisquare test result $\left(P<0.01, \chi^{2}(16)=66.750\right)$ showed the existence of significant relationship between the variables, likewise, a positive correlation result (.101) was ascertained from the Spearman analysis as shown in Table 3, thereby, leading to the rejection of the null hypothesis and the conclusion that the quality of HCFs physical structure and equipment affects enrollees' perception. This finding validates [20]

environmental attribute of quality healthcare and [6] demonstration on the relevance of the physical healthcare environment on the health and well-being of patients.

In contrast, the response from IDI indicated an appalling physical state in the area of general cleaning and sanitations. Furthermore, enrollees treatment were recorded as being conducted in abstract without thorough evidence based investigations from medical diagnostic equipment due to either enrollees coverage plan or the schemes scope of coverage.

\section{Conclusion}

The study shows enrollees perception is affected by the quality of HCFs tangible aspects (physical structure and equipment). This explains that HCF poor management of the physical structures as well as 
inadequacies in functional equipments has an effect on the healthcare services offered to enrollees'.

IDI research finding concludes that, though by policy statement, there is a social health insurance scheme in Nigeria, however in reality; there might be some problems in the dispensation of treatment due to bureaucratic nature of HCFs and the NHIS-HMO coverage policy.

\section{Recommendations}

1. Though the respondent agreed that medical equipment were standard and functional at the HCFs, however, evidences suggested that some HCPs deprive enrollees from evidence-based diagnoses on the pretext of coverage. It is therefore suggested that constructive inspectorate division be instituted to make sure accredited HCPs deliver evidence-based service such as enrollees be allowed access to testing facilities like laboratory in ensuring the desired healthcare result is achieved.

2. In the light of the fact that respondents' are aware of the tangible aspect of healthcare service, the physical ambiance such as flowering, waste management, constant flowing water and scent enhancers should be given priority to ensure consistency in quality health promotion.

3. Enrollees should be allowed to access laboratory as well as other testing facility considered relevant in their illness treatment rather than simple word of mouth as most patients such as those suffering from CIPA and CRPS (Congenital Insensitivity to Pain with Anhydrosis; Complex Regional Pain Syndrome) may not categorically state how they are feeling (symptoms), or where the pain is located.

\section{Declarations}

\section{Ethics approval and consent to participate}

The study was approved by the ethics committee of the Lagos State Government Health Service Commission before the study commenced with an ethical clearance code of: LSHSC/88/S.3/II/257. Written informed consent was obtained from all HCFs/HCPs management as well as the participants.

\section{Consent for publication}

Not applicable

\section{Availability of data and materials}

All data generated or analysed during this study are included in this published article.

\section{Competing interests}

The authors declare that they have no conflict of interests.

\section{Funding}


No funding was received to assist with the preparation of this manuscript.

\section{Authors' Contributions}

MA initiated the research; PB supervised the work, $\mathrm{Cl}$ co-supervised. $\mathrm{PB}, \mathrm{Cl}$ and $\mathrm{MA}$ designed the study including quantitative and qualitative modules. MA drafted the initial manuscript, collected and analyzed the data (questionnaire distribution and interview session). AF, RB, OA assisted with the study protocol including research questions and methods of evaluation. PB assisted with analyzes and interpretation of the quantitative data. $\mathrm{PB}, \mathrm{Cl}, \mathrm{OA}$ assisted with analyzes and interpretation of the qualitative data. MA drafted the final version, which all authors read, edited, and approved the final manuscript.

\section{Acknowledgments}

The authors would like to thank Prof. Rev. Stephen Olugbemiga OWA, Mr. Isaac Akintoyese Oyekola'Dr. Olayinka Onayemi, Oluwaseyi Ibijola; Oludipe Emmanuel and all participant enrollee, and the HCFs/HCPs for their roles in the success of the study.

\section{References}

1. Feigenbaum, A., V. (1951). Quality control: Principles, practice, and administration. New York: McGraw-Hill.

2. Peters, T., \& Waterman, R., (1982). In search of excellence: lessons from America's best run companies. New York: Harper and Rowe.

3. Zeithaml, V., A. \& Bitner, M., J. (1996). Services Marketing, New York: McGraw-Hill

4. Donabedian, A. (1980). The definition of quality and approaches to its assessment. Ann Arbor: Michigan Health Administration Press

5. Mosadeghrad, A. M. (2012b). Towards a theory of quality management: an integration of strategic management, quality management and project management. International Journal of Modelling in Operations Management, 2, 89-118. doi:10.1504/ijmom.2012.043962.

6. Dijkstra, K., Pieterse, M., E, \& Pruyn, A. (2006). Physical environmental stimuli that turn healthcare facilities into healing environments through psychologically mediated effects: systematic review. Journal of Advanced Nursing. 56(2),166-181.

7. Drahota, A., Stores, R., Ward, D., Galloway, E., Higgins, B., \& Dean, T. (2005). Sensory environment on health-related outcomes of hospital patients. (Protocol). Cochrane Database of Systematic Reviews. [DOI:10.1002/14651858.CD005315]

8. Ulrich, R. (1984). View Through a Window May Influence Recovery from Surgery. Science (224), 420421.

9. Husserl, E., 2001, The Shorter Logical Investigations. London and New York: Routledge. An abridged edition of the preceding. 
10. Husserl, E. Zur Phänomenologie des inneren Zeitbewußtseins (1983-1917). Ed. R. Boehm. The Hague: Martinus Nijhoff, 1966; On the Phenomenology of the Consciousness of Internal Time. Trans. J. Brough. Dordrecht: Kluwer Academic Publishers, 1991.

11. Broadbent, D. (1958). Perception and Communication.London: Pergamon Press.

12. Gleitman, M. (1996). Basic Psychology. New York: W.W. Norton and Company

13. Martin, M. (2001). Beyond Dispute: Sense-Data, Intentionality and the Mind-Body Problem, in History of the Mind-Body Problem, edited by Tim Crane and Sarah Patterson, Routledge.

14. Martin, M. (2002). The Transparency of Experience.Mind \& Language, 17, 376-425.

15. Martin, M. (2004). The Limits of Self-Awareness.Philosophical Studies, 120, 37-89.

16. Martin, M. (2006). On Being Alienated. in Perceptual Experience, edited by Tamar Gendler \& John Hawthorne, Oxford University Press.

17. Pett, M., A. Lackey, N., R. \& Sullivan, J., J. (2003). Making Sense of Factor Analysis: The use of factor analysis for instrument development in health care research. Califonia: Sage Publications Inc.

18. Garson, D. G. (2008). Factor Analysis: Statnotes. Accessed March 22, 2019, from North Carolina State University Public Administration Program.

19. Ndiyo, N. A. (2005). Fundamentals of research in behavioral sciences and humanities. Calabar: Wusen Publishers.

20. Mosadeghrad, A. M. (2013). Healthcare service quality: Towards a broad definition. International Journal of Health Care Qual Assur. 26, 203-219. doi: 10.1108/09526861311311409. 